\title{
LA PESTE
}

\section{Cristina Bajo ${ }^{1}$}

\section{Referencias}

En El Jardín de los Venenos, intenté una semblanza de la Córdoba de finales del S.XVII y principios de XVIII. El eje era la peste y los conflictos con el Obispo Mercadillo. Los libros consultados sobre las epidemias fueron:

*Los Jesuitas en Córdoba, del P. Joaquín Gracia S.J., con muchas referencias sobre las recurrentes epidemias en Córdoba y citas de las Cartas Anuas.

*El Trasplante Cultural - Historia social y cultural del Río de la Plata 15361810- Tomo II-Ciencia, del P. Guillermo Furlong S.J.

*Historia de la Medicina en Córdoba, del Dr. Félix Garzón Maceda.

*Los apuntes sobre el libro del Dr. Thomas Sydenham sobre la peste en Londres a finales del S. XVII, y la historia del Vinagre de los Cuatro Ladrones fueron tomados de M.D., revista internacional de medicina, en su versión en español.

\section{Aclaración}

Entre 1635 y hasta finales del S. XVIII, hubo diferentes epidemias, y la que yo relato es una mezcla entre la del 1635 y del 1717-19.

Los jesuitas que nombro, salvo el P. Allen, son reales, como lo son sus actuaciones, pero pertenecen a la peste de 1635-38.

Se cree que el libro de Sydenham lo trajo el P. Falkner S.J., pero años después de este relato.

Lo que está en bastardilla es textual

revista.

Esta versión abreviada de un capítulo es algo diferente para adecuarla a la C.B.

1- Cristina Bajo nació el 17 de junio 1937 en Córdoba, Argentina. Cuando era pequeña su familia se mudó a Cabana, un pequeño pobrado de las sierras de Córdoba; donde inició su amor por la literatura. Transitó sus estudios en una escuela de monjas en Unquillo. Estudió Magisterio en el colegio de Espíritu Santo, y trabajó como maestra rural, entre otras actividades.

Entre su obra, se encuentran novelas románticas históricas, antologías de cuentos basados en leyendas argentinas. En 1998, fue elegida "Mujer del Año" de la provincia de Córdoba. En 2004 fue galardonada con el Premio Literario Academia Argentina de Letras por su antología "Tú, que te escondes" y en 2005 con el Premio Especial Ricardo Rojas del Gobierno de la Ciudad de Buenos Aires por "El jardín de los venenos", originalmente titulado "Sierva de Dios, ama de la Muerte" 
El año comenzó con un temporal que desbordó el Calicanto. La crecida no llegó a ser tan grave como la de 1622, que dañó Santo Domingo, inundó la cárcel y asustó a las Catalinas, que fueron a cobijarse en lo de don Pedro Luis de Cabrera. Tampoco fue como la de 1671, que llegó de noche, cobró cientos de vidas y la gente tuvo que refugiarse en La Merced.

Esta anegó sótanos y derrumbó barracas, menoscabando reservas de granos y alimentos, y devastando las cosechas. Las parroquias aumentaron la "sopa de indigentes" y la leche para los críos, y los ricos fueron conminados desde el púlpito a prestar ayuda.

Al final del verano se presentó la disentería, que mutó en dolores de cabeza, fiebres y temblores del cuerpo: era el preludio de un mal temible: la viruela infecciosa que desembarcó en El Callao y atravesó Salta, Tucumán y Santiago antes de entrar a Córdoba.

Al principio se cobró víctimas aisladas, ignoradas por lo distantes para, finalmente, tomar la ciudad: uno de los monaguillos de San Francisco, durante la misa, se volvió hacia los fieles con el rostro arrebolada y la respiración ansiosa, soltó la patena y cayó de bruces con un lamento horrible.

La gente se atropelló para salir del templo y en segundos Dios quedó tan solo como la noche en que cantaron los gallos y su Hijo fue coronado de espinas.

El Padre Allen S.J. pensaba -mientras se desvelaba leyendo los textos de medicina de la Biblioteca Grande de la Universidad-, en cómo la peste perdonaba a alguien en una casa que, de seis, morían cinco. ¿Por qué el sexto se salvaba? No lo sabía, pero había notado algo que su hábito le permitía aceptar, aunque su formación científica miraba con recelo: todos ellos cuidaban de los otros sin mostrar el mínimo temor.

¿A qué respondía eso? ¿A la fe? ¿A cierta condición alquímica de su cuerpo? ¿A la protección divina que lo convertía en el "gorrión elegido" quién, según el Antiguo Testamento, sobrevivía a la bandada para dar testimonio?

Y mientras buscaba un "detente" a la Amarga Dama sin Piedad, las campanas doblaban a muerte, una sístole y una diástole melancólica sobre la ciudad de las torres.

Finalmente, sucedió lo ineludible: el mal se encarnizó en el convento, atacando desde la gente de servicio hasta los más altos cargos y tuvo que hacer, de la Casa, un hospital, al mismo tiempo que él corría por la ciudad con un Hermano coadjutor apellidado Gutiérrez.

Era éste de Castilla la Vieja, experto barbero y excelente cirujano. Tenía facilidad para las hablas africanas, y allí donde los negros morían sin hacerse entender, él se les acercaba, los lavaba e intentaba una de sus lenguas, lo que traía un gran alivio a los infelices, pareciéndole al P. Allen que algunos sanaban porque, comunicándose con aquel viejo fuerte, con un rostro que envidiaría el Cid, les volvía la esperanza al cuerpo.

Tal era su ascendiente, que logró entre ellos buenos enfermeros que lo seguían por las rancherías de los conventos, donde caían como moscas los esclavos.

En su recorrido, Allen -seguido por el Hermano Hansen que cargaba el maletín de cirujano y el del viático-, llevaba la estola de confesar puesta y entraba en las moradas sin ceremonias, casi con los modales de un ujier.

Mientras actuaba como médico, usaba la mascarilla y los guantes, que quemaba antes de salir de la casa -exigía al llegar un brasero encendido-, pero cuando daba la Extremaunción, dejaba al aire sus manos y su boca, aunque luego se desinfectara.

Regresaban de noche, extenuados, presintiendo la fiebre a sus espaldas, y cuando la gramilla ahogaba sus pasos, oían los ayes tras los postigos. A veces, un grito rompía el vidrio ahumado del cielo, y ellos, estremecidos, se santiguaban y tocaban a la puerta, cual si fuera el Destino que pasara a recoger el alma del extinto.

Surgiendo de sótanos, de criptas donde dormían los sudarios de las monjas muertas, ascendían las preces de las Teresas, que se turnaban para que ni un segundo del día dejara de contar con su plegaria.

Antes de acostarse, el P. Allen se bañaba, indicando al joven belga que hiciera lo mismo. Luego bebía un cordial, comía algo, y abría el libro del doctor Thomas Sydenham en el capítulo "Sobre la constitución epidémica de parte del año 1669 y de los años 1670, 71 y 72, en Londres".

La descripción del mal, la continuidad de las plagas -el cólera morbo, las fiebres disentéricas, las viruelas, la escarlatina, se desplazaban unas a otras- y la sensatez de los remedios que proponía, eran notables.

Antes de apagar la vela, pensaba en la joven Zúñiga y su agudeza para detectar síntomas, sospechando que sabía más de lo que su modestia le revelaba.

¿Su modestia o su astucia?, se preguntaba, para pensar, cuando caía en el sueño, que era una pena que fuera mujer. Si hubiese sido varón, hubiera podido tomarla 
por discípulo: intuía que era aún mejor que su ayudante, a quien vivía en el temor de perder, por su sentido misional y su indiferencia ante el contagio.

La Hermana Sofronia, esa erudita hermética y retraída, no había elegido porque sí a quién era ajena a la comunidad y sospechaba que le había transmitido más ciencia de la que él tenía noticia; bien conocía la hermandad de las mujeres, esa cofradía sin libros ni reglas: era la antigua asociación de los esclavos, de los menos fuertes, de los disidentes en peligro. Ningún papel denunciaba, todo se hacía en secreto y en susurros: los susurros, al menos en aquel siglo que comenzaba, no eran prueba ante ningún tribunal. Era madrugada aun cuando se levantaba a preparar el legendario "vinagre de los cuatro ladrones". La fórmula se había conocido durante la epidemia que causó más de 50.000 víctimas en la región de Tolouse, entre 1628 y 1631, en cuyo Parlamento quedó registrada el hecho y la receta. Los cuatro ladrones a los que aludía el remedio eran salteadores que robaban a los apestados; al ser detenidos, asombrados los jueces de que no se hubieran contagiado, confesaron tener un remedio eficacísimo, y pidieron se les conmutara la pena de muerte a cambio de la receta.

El preparado constaba de "2,5 I de vinagre, $40 \mathrm{~g}$ de absenta, 40 de romero, 40 de salvia, 40 de menta, 40 de ruda, 40 de lavanda, $5 \mathrm{~g}$. de canela, 5 de girasol, 5 de nuez moscada y $5 \mathrm{~g}$ de ajo. Se añadía alcanfor disuelto en $4 \mathrm{~g}$ de ácido acético cristalizado y se reposaba por diez días.

De uso rigurosamente externo, se usaba contra enfermedades infecciosas y contagiosas: se frotaban las manos, la cara y el cuerpo si uno estaba muy expuesto; se quemaba, además, en las casas y decían que dándolo a oler, resucitaba en caso de síncope."

EI P. Allen no estaba seguro del porqué de su virtud, pero ocho de cada diez veces preservaba del contagio. Él creía más en el "cuatroladrones" que en las fumigaciones de albahaca y mejoranas usadas "cuando el daño surgía de los humores interiores que buscaban el desahogo en pústulas exteriores."

Un día encontró a Doña Sebastiana en la calle, sentada en una silla que alguien le acercara; una criada sostenía un parasol sobre su cabeza y a su lado, en el suelo, había una cesta de comida o de remedios.

_Ha muerto un angelito_les dijo_; los padres están muy enfermos y les he dado alivio. Ahora espero que vengan a buscar el cuerpo. Prometí que será enterrado cristianamente.

$Y$ al levantar el rostro, el sacerdote vio en él una indecible tristeza.

_iAh, su merced, qué triste es ser mujer! _ confesó ella. _Creo que ningún hombre puede entender el dolor de perder un niño al que se esperó durante meses, acunándolo en las entrañas...

Como llegaran los de la Cofraadía, se despidieron. La escena, como un feo sueño, perseguiría al jesuita por años: la joven, la calle vacía y ocre, la mestiza con el parasol, y el carro con un caballo esquelético -cual corcel apocalíptico que trae hambre y peste-, que se acercaba a paso tardo hacia la modesta vivienda.

En Alta Gracia, murió el Hermano Eladio -que suplía su poca ciencia con mucha dedicación- junto a esclavos, indios y religiosos en tal cantidad que el Hermano Gartner, tejedor, pidió dejar la estancia "por no tener gente para su obraje".

También en Santa Catalina la mortandad de africanos y sacerdotes había sido trágica, salvándose, por aislada, La Candelaria.

Alguien escribió: "En la ciudad inerte, con la palidez de un enfermo, se prolonga la languidez de una agonía."

Finalmente, el mal cedió aunque rezongó por la región tres años más. Pero como sucediera antes y sucedería por siglos, Córdoba resurgió entre las cenizas.

(De El jardín de los venenos) 